\title{
A política de assistência social em cidades gêmeas da fronteira gaúcha
}

\author{
Vini Rabassa da Silva \\ Daiane da Rosa Ugoski
}

\section{SciELO Books / SciELO Livros / SciELO Libros}

SILVA, V. R., and UGOSKI, D. R. A política de assistência social em cidades gêmeas da fronteira gaúcha. In: COSTA, L. C., NOGUEIRA, V. M. R., and SILVA, V. R., orgs. A política social na América do Sul: perspectivas e desafios no século XXI [online]. Ponta Grossa: Editora UEPG, 2013, pp. 219-232. ISBN 978-85-7798-231-8. Available from: doi: $10.7476 / 9788577982318.0010$. Also available in ePUB from: http://books.scielo.org/id/rfv9p/epub/costa-9788577982318.epub.

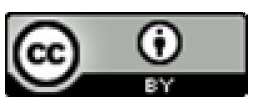

All the contents of this work, except where otherwise noted, is licensed under a Creative Commons Attribution $\underline{4.0 \text { International license. }}$

Todo o conteúdo deste trabalho, exceto quando houver ressalva, é publicado sob a licença Creative Commons Atribição 4.0.

Todo el contenido de esta obra, excepto donde se indique lo contrario, está bajo licencia de la licencia Creative Commons Reconocimento 4.0 . 


\section{A política de assistência social em cidades}

gêmeas da fronteira gaúcha

S Vini Rabassa da Silva, Daiane da Rosa Ugoski

\section{Introdução}

A construção deste texto foi motivada pela participação em seminários com a presença de pesquisadores de países do Mercosul (Argentina, Paraguai e Uruguai) os quais têm destacado questões referentes à política de saúde na fronteira, por vezes associada à previdência social, devido aos determinantes decorrentes do exercício laboral. Os autores Nogueira (2005a, 2007); Dal Prá (2006) e Simionatto (2007), da região sul do Brasil, têm feito dos problemas encontrados no entorno das cidades fronteiriças a fonte de estudos para questões ligadas à área da saúde. A realização de um levantamento bibliográfico confirmou que em âmbito nacional as discussões e produções científicas relacionadas à política da assistência social em regiões fronteiriças são raras.

Diante disso, a apresentação deste texto pretende demarcar o resultado de uma primeira aproximação com esta temática, tendo as cidades gêmeas localizadas na fronteira gaúcha como foco, em busca de repercussões e desafios do território fronteiriço à política de assistência social no Brasil.

Iniciando com uma breve caracterização da área geográfica, apresenta-se a seguir o resultado de um estudo realizado nos relatórios das Conferências Nacionais de Assistência Social, para identificar como a questão da fronteira aparece registrada. E, posteriormente, aponta-se o trabalho previsto pelo Ministério do Desenvolvimento Social e Combate à Fome (MDS). Ainda destacando que esta é uma primeira exploração da temática, com a intenção de instigar a sua continuidade, apresenta-se, ao final, algumas questões consideradas como desafios emergentes destes territórios para a Política de Assistência Social.

\section{Identificação das cidades gêmeas do Rio Grande do Sul}

A Faixa de Fronteira do Brasil é hoje definida segundo classificação da Constituição Federal de 1988 como a extensão geográfica localizada "até cento e cinquenta quilômetros de largura, ao longo das fronteiras terrestres" 
(Art.20 \ $2^{\circ}$ ), e recebe por parte do Estado, atenção especial, “[...] é considerada fundamental para defesa do território nacional, e sua ocupação e utilização serão reguladas em lei." (BRASIL, 2011, p.28).

Segundo a base territorial do Programa de Desenvolvimento em Faixas de Fronteira (PDFF, 2005), esta área de limite territorial do Estado é classificada em três macrorregiões denominadas de Arcos, a saber: Arco Norte (Amapá, Pará, Amazonas, Roraima e Acre), Arco Central (Rondônia, Mato Grosso e Mato Grosso do Sul) e o Arco Sul (Paraná, Santa Catarina e Rio Grande do Sul), que abrange 418 municípios, dos quais 197 encontram-se no RS, abrangendo dez cidades gêmeas. A região Arco Sul é aquela que dispõe de maior influência dos processos de integração econômica e transfronteiriça, em consequência do Mercosul (BRASIL, 2005). Divide-se em três sub-regiões: sub-região Portal do Paraná, sub-região Vales Coloniais Sulinos, e sub-região Fronteira da Metade Sul do Rio Grande do Sul (RS).

As denominadas cidades gêmeas por serem divididas apenas pela linha de fronteira são a melhor expressão da problemática desta região, pois nelas se concentram tanto a potencialidade da integração econômica e cultural como os efeitos negativos das desigualdades regionais. Geralmente distantes dos centros decisórios são cidades com menor infraestrutura de serviços públicos e opções de mercado de trabalho, concentrando grande número de pessoas sem proteção de direitos trabalhistas que sobrevivem de atividades informais.

Por outro lado, a vizinhança com cidades de outros países, induz a interações intensas, que levam estas cidades a compartilhar um fluxo contínuo de cidadãos, aspectos culturais, conflitos e expectativas em obter por parte do Estado o desenvolvimento de ações que correspondam a esta realidade de cidade gêmea. Assim, os desafios de atuação governamental nesta região, vão além de desafios geográficos, incorrendo no campo econômico, social, político e cultural, tendo em vista que a fluidez do fluxo transfronteiriço, a configura como "espaço-teste de políticas públicas de integração e cooperação” (MINISTÉRIO DA INTEGRAÇÃO NACIONAL, 2005, p.21). no RS.

O quadro a seguir traz a identificação das cidades gêmeas localizadas 
Quadro 1 - Identificação das cidades gêmeas no RS

\begin{tabular}{|c|c|c|c|c|c|c|}
\hline $\begin{array}{c}\text { Municípios } \\
\text { RS }\end{array}$ & $\begin{array}{c}\text { Extensão } \\
\mathbf{K m}^{\mathbf{2}}\end{array}$ & $\begin{array}{c}\text { Total de } \\
\text { hab. }\end{array}$ & IDH $^{\mathbf{1}}$ & $\begin{array}{c}\text { Porte do } \\
\text { município }^{2}\end{array}$ & $\begin{array}{c}\text { Cidade } \\
\text { Gêmea }\end{array}$ & $\begin{array}{c}\text { País } \\
\text { fronteiriço }\end{array}$ \\
\hline Aceguá & $1.549,391$ & 4.394 & - & Pequeno I & Aceguá & Uruguai \\
\hline $\begin{array}{c}\text { Barra do } \\
\text { Quaraí }\end{array}$ & $1.056,149$ & 4.012 & 0,78 & Pequeno I & Bella Unión & Argentina \\
\hline Chuí & 202,553 & 5.917 & 0,81 & Pequeno I & Chuy & Uruguai \\
\hline Itaqui & $3.404,053$ & 38.159 & 0,80 & Pequeno II & Alvear & Argentina \\
\hline Jaguarão & $2.054,392$ & 27.931 & 0,76 & Pequeno II & $\begin{array}{c}\text { Rio } \\
\text { Branco }\end{array}$ & Uruguai \\
\hline Porto Xavier & 280,511 & 10.558 & 0,76 & Pequeno I & San Javier & Argentina \\
\hline Quaraí & $3.147,647$ & 23.021 & 0,78 & Pequeno II & Artigas & Uruguai \\
\hline $\begin{array}{c}\text { Santana do } \\
\text { Livramento }\end{array}$ & $6.950,388$ & 82.464 & 0,80 & Médio & Rivera & Uruguai \\
\hline São Borja & $3.616,035$ & 61.671 & 0,80 & Médio & SanTomé & Argentina \\
\hline Uruguaiana & $5.715,791$ & 125.435 & 0,79 & Grande & $\begin{array}{c}\text { Passo de Los } \\
\text { Libres }\end{array}$ & Argentina \\
\hline
\end{tabular}

Fonte: Quadro construído pelas autoras a partir de dados disponibilizados pelo MDS.

Observa-se que entre as dez (10) cidades gêmeas da fronteira gaúcha, a maioria (7) está localizada em municípios classificados como de pequeno porte pela política de assistência social. No que se refere ao IDH, constata-se que há relativa semelhança entre elas, considerando que o menor índice é 0,76 (Jaguarão e Porto Xavier) e o maior índice é de 0,81 (Chuî), sendo que três municípios têm IDH 0.80 considerado alto (Santana do Livramento, São Borja e Itaqui), e as demais são classificadas como de médio desenvolvimento humano de acordo com os critérios usados para cálculo deste índice.

Entretanto, embora compartilhem de vários determinantes econômicos, culturais, sociais e políticos, estas cidades possuem especificidades. Assim, por exemplo, os municípios de Jaguarão e Chuí, na fronteira com Uruguai,

\footnotetext{
1 "É obtido pela média aritmética simples de três subíndices, referentes à Longevidade (IDH-Longevidade), Educação (IDH-Educação) e Renda (IDH-Renda)." Disponível em: $<$ http://www.pnud.org.br/atlas/ranking/IDH_Municipios_Brasil_2000.aspx?indiceAccordion =1\&li=li_Ranking2003>. Acesso em: 20 ago. 2010.

Municípios com IDH-M até 0,499 têm desenvolvimento humano considerado baixo; os municípios com índices entre 0,500 e 0,799 são considerados de médio desenvolvimento humano; municípios com IDH-M maior que 0,800 têm desenvolvimento humano considerado alto.

2 Segundo critério de classificação adotado pela política de assistência social para os municípios considerando a densidade populacional: Peq. I (até 20.000 hab.); Peq. 2 (de 20.001 a 50.000 hab.); Médio (de 50.001 até 100.000 hab.); Grande (de 100.001 até 900.000 hab.) e Metrópoles (mais 900.000 hab.).
} 
têm cidades gêmeas cuja base econômica são os Free Shops. Porém, Jaguarão possui como base a criação de bovinos e ovinos, além de uma considerável plantação e indústria de beneficiamento do arroz (IBGE, 2011), enquanto o Chuí brasileiro apresenta estagnação econômica, com fechamento e transferência de estabelecimentos comerciais para o outro lado da fronteira (FERREIRA, 2009). Conforme consta no Programa de Desenvolvimento da Faixa de Fronteira,

No Sudoeste do Rio Grande do Sul (Campanha Gaúcha), na divisa com o Uruguai e a Argentina, as interações são do tipo sináptico-estrutural: as relações tanto no urbano como no rural tem uma longa história comum, com fazendas que se estendem de um lado a outro da fronteira, forte intercâmbio cultural e de trabalho [...] e articulações promovidas ativamente pelos Estados durante anos. A tradicional presença de postos do Exército na Campanha Gaúcha (antiga frente militar) foi concebida para a defesa do território, mas faz anos que fortalece os laços com o país vizinho. (MINISTÉRIO DA INTEGRAÇÃO NACIONAL, 2005, p.147).

No entanto, é comum entre as cidades gêmeas, segundo dados do Ministério da Integração Nacional (MIN, 2010), a falta de acesso aos bens e serviços públicos, falta de segurança pública, abandono pelo Estado, ausência de coesão social e precárias condições de acesso à cidadania em função do compartilhamento socioeconômico, que contrasta com a expectativa em torno do Mercado Comum do Sul (Mercosul) criado pelo Tratado de Assunção (1991).

Segundo o Ministério da Integração Nacional (2005), devido às interações fronteiriças históricas com grande potencial de integração, as cidades gêmeas devem ser priorizadas pelo governo ao desenvolver políticas fronteiriças e ações voltadas para o desenvolvimento social em faixa de fronteira, articulando ministérios e produzindo ações, para construção de políticas públicas com capacidade para dar conta das assimetrias regionais, culturais e econômicas.

Entretanto, ainda há dificuldades para elaboração e efetivação de políticas públicas não apenas em âmbito nacional, mas também entre os países membros do Mercosul de forma a beneficiar o desenvolvimento social e reduzir históricas desigualdades socioeconômicas.

\section{A problemática da fronteira nas Conferências de Assistência Social: um estudo exploratório}

Embora não tenha ainda merecido maior destaque em produções científicas, a preocupação com a região fronteiriça não é exclusividade de áreas como saúde e defesa. Um levantamento realizado nos relatórios finais das 
Conferências Nacionais de Assistência Social evidencia manifestações indicadoras da necessidade de uma atenção especial para esta região. As deliberações da I Conferência Nacional de Assistência Social (CNAS), que ocorreu em 1995, apresentam a preocupação em garantir "uma política diferenciada da área de Assistência Social para os municípios de fronteira, buscando-se o estabelecimento de parceria com entidades de âmbito internacional" (I CNAS, $8^{\mathrm{a}}$ deliberação).

Na III CNAS, em 2001, a área de fronteira internacional é citada como uma das prioridades nos critérios de financiamento. Porém, no eixo "Critérios de Partilha de Recursos entre Benefícios, Serviços, Programas e Projetos”, o qual debateu esta questão, não houve definição de responsáveis, ou de tempo para estabelecimento dos critérios por parte da plenária final, conforme consta em uma pequena nota nas deliberações desta Conferência.

Novamente, a questão fronteiriça aparece nas deliberações da V CNAS realizada em dezembro de 2005, nas Metas de Gestão do Sistema Único de Assistência Social (SUAS), (especificamente a Meta 11), referente à construção de Centros de Referência de Assistência Social (CRAS), inclusive em áreas de fronteira. Na mesma Conferência, foi apresentada a "Fotografia da Assistência Social no Brasil na Perspectiva do SUAS", enquanto parte do processo de construção do SUAS - Plano 10 (Plano de Metas Decenais da Política de Assistência Social) para implantação do sistema em âmbito nacional, tendo em vista que a Nova Política Nacional de Assistência Social fora aprovada em 2004. Frente às informações prestadas pelos estados, o Álbum de Fotografias trouxe para o debate a preocupação com a PNAS em regiões de fronteira com outros países. Segundo Aldaíza Sposati, coordenadora do Álbum:

Os estados brasileiros, que se limitam geograficamente com outros países, principalmente o Mato Grosso do Sul com a Bolívia, e o Acre, com o Peru, incluem na agenda o direito a atenção ao desamparo da população de fronteira. Os direitos sociais bilíngues precisam ser aprofundados no Mercado Comum do Sul (Mercosul) e nas demais fronteiras do Brasil. [...] Ciganos, andarilhos, até mesmo esportistas ou aventureiros, reclamam a acolhida que certamente requer a articulação da assistência social com outras políticas sociais. A população em situação de rua, em qualquer momento do ciclo de vida, da infância à velhice, exige prioridade na inclusão em proteção social especial e básica. (SPOSATI, 2005, p.14).

Assim, foi reconhecida a necessidade de intervenções intersetoriais e de efetivação de proteção básica e especial para a população de fronteira, tendo em vista os crescentes desafios postos com o agravamento da questão social, requerendo respostas imediatas no campo social. Esta realidade pressupõe ampliar a atuação e a responsabilidade da assistência social, já que para garantir o acesso à 
proteção social por parte da população transfronteiriça, é preciso estender direitos, e superar a questão da cidadania atrelada à nacionalidade.

Recentemente, a VIII CNAS realizada em dezembro de 2011, trouxe mais uma vez a fronteira para debate na oficina intitulada "SUAS e a questão das fronteiras", que foi enriquecido por diferentes visões apresentadas pelos participantes. A Secretária de Estado de Trabalho e Assistência Social do Mato Grosso - SETAS $/ \mathrm{MT}^{3}$ abordou os desafios do SUAS na faixa de fronteira daquele estado, apresentando os aspectos geográficos, sociais e históricos; a organização do SUAS; o perfil da demanda que acessou os serviços por municípios; a tipologia da oferta dos serviços, apontando a inadequação nas equipes de referência, estrutura de atendimento e gestão dos serviços (2010/2011), tornando claro os limites e expectativas do SUAS para a fronteira. Um professor da Faculdade União das Américas e assistente social da Universidade Federal da Integração Latino-Americana - Foz de Iguaçu/PR priorizou a fronteira de Foz do Iguaçu (fronteira Brasil/Paraguai) e trouxe para o debate a situação de vulnerabilidade social, com questões relacionadas à cidadania e direitos de brasiguaios. Demonstrou que a busca por serviços socioassistenciais tem sido ampliada, sendo necessário rever questões voltadas à cidadania, direitos sociais e justiça social, considerando que a discussão em torno do acesso está diretamente interligada a essas questões. Também, a Assistente Social e Bióloga, Chefe da Divisão de Ações de Média Complexidade da Secretaria de Estado do Trabalho e Bem Estar Social de Roraima - SETRABES/RR, destacou o problema do tráfico humano e enfatizou a fronteira de Roraima como uma das principais rotas de tráfico.

Assim, foram destacados pelos oficineiros, nesta última Conferência Nacional, tanto problemas gerais quanto específicos de fronteiras. Entretanto, pode-se observar que as discussões do Arco Sul ficaram restritas à fronteira Paraná-Brasil/Paraguai, sem abordar especificidades existentes na extensão fronteiriça que chega ao RS.

\section{Ações em âmbito de Mercosul e política da assistência social}

Segundo o Ministério da Integração Nacional (MIN), o governo brasileiro vem proporcionando a construção de políticas públicas e ações voltadas a atender diferentes áreas (saúde, educação, agricultura familiar...), buscando, também, ampliar coberturas socioassistenciais destas regiões fronteiriças, tendo em vista que "o Desenvolvimento da Faixa de Fronteira configura-se como importante diretriz da política nacional e internacional brasileira.” (2009, p.11).

\footnotetext{
Destaca-se que a identificação das funções dos participantes que fizeram os pronunciamentos aqui citados corresponde ao período de realização da conferência.
} 
Desde a sua criação, no ano de 2004, o Ministério do Desenvolvimento Social (MDS) tem agregado grande parte das políticas sociais responsáveis delo desenvolvimento social, provendo proteção básica (famílias/indivíduos em situação de vulnerabilidade social) e proteção especial (famílias/indivíduos em situação de risco pessoal ou social); conduzindo políticas de transferência de renda (o Bolsa Família é o carro-chefe, seguido de outros programas, como o Benefício de Prestação Continuada), segurança alimentar e nutricional (através de programas que possibilitam ao cidadão acessar alimentos e água, além de ter apoio para a produção e distribuição de alimentos) e desenvolvimento territorial com destaque para o Programa Territórios da Cidadania, criado em 2008, para atender prioritariamente, a uma demanda social composta por quilombolas, terras indígenas, famílias assentadas, agricultores familiares e pescadores. Assim, o MDS vem trabalhando a construção de projetos através da parceria com a sociedade, objetivando combater a pobreza, prover segurança alimentar e gerar renda conforme a necessidade de cada território.

Além destas ações previstas para todo o território nacional, o MDS vem atuando, juntamente com outros ministérios em faixas de fronteira, para implementar programas de desenvolvimento social (assistência social, transferência de renda, segurança alimentar e saúde). Particularmente, a política de assistência, através de ações intersetoriais, tem se dirigido para o combate ao crack, disponibilizando uma rede de proteção social básica, através dos CRASs, buscando reconhecer territórios vulneráveis e prevenir situações de risco social. Atua também em parceria no combate à exploração e violência sexual de crianças e adolescentes, ofertando serviços da proteção social especial, através dos Centros de Referência Especializada de Assistência Social (CREAS), em conjunto com o Programa de Ações Integradas e Referenciais de Enfrentamento à Violência Sexual Infanto-Juvenil no Território Brasileiro (PAIR), que hoje alcança 14 cidades gêmeas, fronteira com Argentina, Uruguai e Paraguai.

Além destas atividades, o $\mathrm{MDS}^{4}$ vem atuando em concordância com as diretrizes da política externa, firmando acordos de cooperação, participando de blocos regionais, desenvolvendo atividades relacionadas à avaliação e monitoramento de políticas sociais, realizando eventos (seminários e capacitações) sobre políticas sociais, os quais são abertos a outros países.

Ramos (2006) aponta que o Brasil tem apresentado expansão no campo do desenvolvimento social na cobertura da assistência social através da instituição do SUAS e do programa Bolsa Família. Outro fator que tem diferenciado

\footnotetext{
4 Conforme informações disponíveis em: <http://www.mds.gov.br/acesso-a-informacao/ relacoesinternacionais $>$. Acesso em: 17 fev. 2012.
} 
o Brasil, como aponta o autor, é a Secretaria de Avaliação e Gestão da Informação (SAGI), cuja função é produzir indicadores, desenvolver estudos e realizar a avaliação e monitoramento de políticas, programas, projetos e serviços executados pelo MDS, além de capacitar agentes públicos. A SAGI, segundo Ramos (2006), vem participando inclusive, do Foro Mercosul Social.

Sousa (2008) pontua o acompanhamento realizado pela Secretaria $\mathrm{Na}$ cional de Assistência Social (SNAS) no âmbito da proteção social em cidades gêmeas, o trabalho realizado na implantação dos CREAS através do SUAS, e a participação nas discussões do Mercosul Social. Nos anos de 2006-2007, são destacados os GTs organizados em âmbito de Mercosul - Brasil-Colômbia; Brasil-Venezuela; Brasil-Uruguai. Cabe destacar que conforme Sousa (2008), na Fronteira do RS, o GT Brasil-Uruguai (Santana do Livramento/Rivera), vem ganhando força no combate ao abuso e exploração sexual de crianças e adolescentes além do tráfico de pessoas.

Em âmbito de Mercosul, vem ganhando força a construção do Plano Estratégico de Ação Social do Mercosul que envolve discussão e construção conjunta de políticas públicas voltadas ao desenvolvimento social, erradicação da pobreza, segurança alimentar e garantia de acesso à saúde e assistência social, como direito do cidadão, reduzindo o descompasso entre o desenvolvimento econômico e social, apontado por Draibe (2007), além de ampliar os canais de participação. Existe uma construção conjunta, uma discussão que aponta para a criação de políticas sociais regionais com maior interação entre os campos econômico e social, e interação com países do Mercosul (MARTINS; SILVA, 2011), como forma de atender a população fronteiriça, que não dispõe de nacionalidade brasileira, mas que se encontra dentro dos padrões de vulnerabilidade e risco social e que busca atendimento em serviços brasileiros.

Outro avanço a ser considerado é o plano de ação para a instituição do Estatuto da Cidadania do Mercosul, que amplia a integração social e, sendo efetivado, poderá garantir maior igualdade de direitos (sociais, civis, econômicos) entre cidadãos dos Estados que formam o Mercosul, o que responderia à necessidade de atendimento no campo da assistência por parte de cidadãos uruguaios e argentinos em cidades gêmeas brasileiras.

No entanto, ainda que as discussões apontem para o avanço no campo social, também apontam para a lentidão no campo das decisões. O Plano Estratégico de Ação Social do Mercosul teve início, no campo discursivo, em 2006, na Cúpula de Córdoba, por incentivo dos Presidentes do Mercosul, no entanto, permanece em discussão. A sua efetivação legal poderá trazer grandes avanços sociais, tendo em vista que um dos objetivos prioritários diz respeito ao atendimento de famílias em vulnerabilidade e risco social, nos serviços de assistência social. 


\section{Alguns desafios para a política da assistência social}

Considerando a situação das cidades gêmeas e as propostas existentes para efetivação da política de assistência social em áreas de fronteira, entende-se que há minimamente dois desafios a serem considerados pela PAS: o critério de classificação dos municípios e a concepção de cidadania.

Discutir acesso a programas, serviços e benefícios por residentes na faixa de fronteira do RS, que não possuem cidadania brasileira, leva a questões referentes à gestão e ao financiamento, pois a maior parte dos municípios é de Pequeno Porte I. Conforme a classificação dos municípios apresentada no Quadro 1, das cidades gêmeas do RS, apenas Uruguaiana, cidade gêmea com Passo de Los Libres/Argentina é um município de grande porte, sendo assim, a grande maioria não dispõe dos mecanismos necessários para o enfrentamento das desigualdades sociais, pois a rede de proteção encontra-se simplificada, devido à baixa demanda de proteção especial, o que ocorre de forma semelhante nos municípios de Pequeno Porte II, sendo necessário o encaminhamento para municípios de porte maior, que de acordo com a NOB/SUAS (2005), recebem co-financiamento estadual e federal para atendimento destas demandas. Assim, a baixa demanda quantitativa reduz o repasse de recursos financeiros, a rede de serviços e o quadro técnico, e exige articulação com serviços de outros municípios, às vezes situados a longa distância, e já sem disponibilidade de atendimento.

A questão que se coloca é: como romper com este círculo de baixa demanda quantitativa e pouca disponibilidade local de resolutividade se o co-financiamento depende de dados quantitativos? E, como enfrentar os graves problemas destes territórios sem romper com este círculo reprodutor de políticas públicas de baixa efetividade em municípios de pequeno porte?

Outro desafio a ser enfrentado refere-se à concepção de cidadania. Constam no site do Ministério das Relações Exteriores memorandos de cooperação e acordos binacionais na área da assistência social, no entanto, ainda parece predominar a "política da boa vizinhança" entre países fronteiriços, com base em observação, articulação e conversas que têm gerado alguns resultados positivos. Entende-se que, ainda que o PAIR seja um exemplo de ações articuladas entre países do Mercosul, a ampliação de ações voltadas à potencialização de direitos e cidadania exigirá uma articulação maior entre países e a superação de uma concepção de cidadania atrelada à noção de registro civil, nacionalidade. Somente assim será possível efetivar a diretriz da universalidade dos direitos sociais.

Tais questões emergem no campo da assistência de forma latente, indicando a necessidade de maior aprofundamento através de estudos e debates, pois a questão da cidadania vinculada à nacionalidade, ao território de determinado 
Estado Nação, coloca o cidadão não nacionalizado, o cidadão transfronteiriço, limitado ao acesso de bens, serviços e proteção. Segundo Costa,

o requisito essencial para o acesso aos bens e serviços proporcionados pelas políticas sociais foi o vínculo de cidadania, definido como a relação jurídica que liga o indivíduo à sociedade politicamente organizada, o Estado nacional. (COSTA, 2008, p.135).

Em cidades gêmeas, o constante fluxo de cidadãos transfronteiriços, bem como o compartilhamento de problemas sociais, exige ações no campo da PAS e requer o atendimento a cidadãos, sem nacionalidade brasileira, mas em situação de vulnerabilidade e/ou risco social.

Uma busca nos quadros temáticos de acordos, tratados e convenções bilaterais em vigor para o Brasil ${ }^{5}$, que se encontram disponíveis no site do Ministério das Relações Exteriores, demonstra que a maior parte dos acordos em vigor está direcionada para a Previdência Social, para as relações de trabalho. No campo da colaboração social, são poucos os registros. Brasil/ Argentina dispõe do Ajuste Complementar ao Acordo de Cooperação Técnica para Criação do Instituto Social Brasileiro-Argentino, que busca cooperação intergovernamental, objetivando a troca de experiências além de trabalhar para tornar compatíveis as políticas públicas de caráter social. No Memorando de Entendimento para a Cooperação Brasil/Uruguai, instituído no ano de 1987(anterior à nova política nacional de assistência), já consta o reconhecimento de que estes dois países possuem tanto a experiência, quanto a necessidade de atuar no campo da assistência social.

Porém, na prática, os questionamentos permanecem. Convém lembrar, ainda, que tendo em vista os problemas sociais existentes nas cidades gêmeas, o atendimento às demandas não se esgota com ações imediatas. E, geralmente, os programas com atendimento continuado têm condicionalidades (comprovação de residência, frequência à escola e outros), podendo esbarrar na legislação nacional referente à ausência de cidadania brasileira.

Assim, apesar da complexidade da questão, entende-se como necessária a construção de uma concepção de cidadania para além dos limites de nacionalidade. Segundo Draibe (2007), há necessidade de garantir uma cidadania social através de políticas sociais integradas. O Estatuto de Cidadania do Mercosul e o Plano Estratégico de Ações do Mercosul podem se constituir em mecanismos que ampliarão possibilidades de acesso e reconhecimento à

\footnotetext{
5 Acordos disponíveis no site:

$<$ http://dai-mre.serpro.gov.br/atos-internacionais/bilaterais/1987/b_63/> no entanto, o acordo Brasil/Uruguai não consta nas atividades internacionais do MDS < http://www.mds.gov.br/acesso-a-informacao/relacoesinternacionais>. Acesso em: 17 fev. 2012.
} 
cidadania aos não cidadãos fronteiriços. Entretanto, esta é uma questão complexa que necessita ser pensada/proposta por estudiosos de ciência política, direito internacional, ética e moral, mas para a qual, sem dúvida, as ciências sociais têm muito a contribuir em relação à materialidade da questão e, particularmente, às políticas sociais para provocar ações consequentes.

\section{Considerações finais}

As cidades gêmeas, na fronteira gaúcha, constituem um território cuja especificidade é decorrente não só da cultura patrimonialista e conservadora existente na região, como também das dificuldades decorrentes de sua localização geográfica, envolvendo questões que ultrapassam as políticas sociais e econômicas nacionais, requerendo ampliar o debate em âmbito de Mercosul. Elas são marcadas por expressões da questão social decorrentes da desigualdade social, convivendo com situações de extrema vulnerabilidade e risco social, que atingem cidadãos brasileiros, cidadãos transfronteiriços sem cidadania brasileira e outros em constante mobilidade, apesar de gozarem de um IDH de médio a alto.

A criação do Mercosul e de todas as iniciativas posteriores aponta para o fortalecimento de uma agenda social entre os países membros, prevendo colaboração para o combate à pobreza, redução das desigualdades sociais e garantia de desenvolvimento social, com ênfase ao enfrentamento da violência sexual e ao trabalho infantil, linhas das quais o MDS participa, juntamente com outros ministérios que se encontram em consonância em diferentes áreas (MARTINS; SILVA, 2011).

No entanto, as iniciativas voltadas à proteção social básica e especial com construção de políticas formuladas de forma integrada com os países vizinhos para responder de forma efetiva às necessidades sociais ainda são tímidas e a implantação do SUAS, norteado pela lógica de repasse de recursos de acordo com a densidade populacional dos municípios, não consegue responder a territórios classificados de pequeno porte, porém distantes de municípios providos de serviços de referência e, ao mesmo tempo, com um contingente de população desprotegida de direitos sociais pela sua inserção no mercado informal, além de abrangerem um fluxo contínuo de cidadãos migrantes.

Os dados obtidos através de uma primeira exploração sobre a política de assistência social e Mercosul, tendo como foco a faixa de fronteira e, ainda mais especificamente, das cidades gêmeas localizadas na fronteira gaúcha, indicam a validade e exigência de dar continuidade a estudos sobre esta temática.

Assim, ratifica-se a importância de estudos e pesquisas que possam dar maior visibilidade para as possibilidades, limites, retrocessos e potencialidades 
de efetivação de políticas regionais integradas em âmbito de Mercosul, dirigidas especialmente ao contingente de pessoas consideradas não cidadãos, marcadas concretamente pela ausência de políticas públicas materializadoras de direitos sociais e impulsionadoras do desenvolvimento de autonomia pessoal, familiar e social. Destaca-se, por fim, que isso não pode implicar o reforço à focalização e assistencialização, ao contrário, deve incentivar a ruptura com ações meramente populistas, paliativas ou discursivas, paralelamente à provocação para que sejam implementadas ações imediatas capazes de estabelecer bases sólidas a um enfrentamento efetivo da desigualdade social.

Considera-se, ainda, de fundamental importância a promoção do debate acerca da PAS em cidades gêmeas do RS, para descobrir os principais desafios que a execução desta política na faixa de fronteira tem enfrentado e as possibilidades existentes para que a população que se encontra inserida nesta política não só alcance os direitos sociais, mas conquiste a sua autonomia. Isto exige ampliar discussões em âmbito de Mercosul e definir articulações entre políticas sociais e econômicas para atender de forma efetiva a população que se encontra em vulnerabilidade e risco social. Enquanto o Estatuto de Cidadania do Mercosul e o Plano Estratégico de Ação Social do Mercosul permanecem no campo de discussões, a realidade fronteiriça exige urgência de ação.

Por fim, ratifica-se a importância da contribuição da política da assistência social como responsável pela oferta de programas e serviços de forma setorial, ou intersetorial, capaz de enfrentar a dura realidade daqueles que, vivendo na fluidez do limite de uma nação, sobrevivem como não cidadãos.

\section{Referências}

BRASIL. Constituição da Republica Federativa do Brasil. Texto constitucional promulgado em 5 de outubro de 1988, com as alterações adotadas pelas emendas constitucionais n. $1 / 92$ a 67/2010, pelo Decreto n. 186/2008 e pelas Emendas Constitucionais de Revisão n. 1, 6/94. Brasília: Senado Federal, Subsecretaria de Edições Técnicas, 2011.

Ministério do Desenvolvimento Social e Combate à Fome. Política Nacional de Assistência Social (PNAS). Brasília: MDS/SNAS, 2004.

Brasilia: MDS/SNAS, 2005.

Norma Operacional Básica da Assistência Social (NOB/SUAS). Conferência Nacional de Assistência Social, 1. Brasília, 1995.

. Conferência Nacional de Assistência Social, 3. Brasília, 2001.

Conferência Nacional de Assistência Social, 5. Brasília, 2005.

. Conferência Nacional de Assistência Social, 7. Brasília, 2008. 
Conferência Nacional de Assistência Social, 8. Brasília, 2010.

Relações internacionais. Disponível em: <http://www.mds.gov. br/ acesso-a-informacao/relacoesinternacionais>. Acesso em: 17 fevereiro 2012.

. MINISTÉRIO DA INTEGRAÇÃO NACIONAL. Secretaria de Programas Regionais. Programa de Desenvolvimento da Faixa de Fronteira. Brasília, 2005. Disponível em: <www.mi.gov.br/download/download.asp?endereco=/pdf/...>. Acesso em: 17 nov. 2011.

Faixa de fronteira programa de promoção do desenvolvimento da Faixa de Fronteira - PDFF. Brasília: 2009. Disponível em: < http:/ / portal.cenad. gov.br/programa-de-promocao-do-desenvolvimento-da-faixa-de-fronteira-pdff $>$. Acesso em: 17 fevereiro 2012.

COSTA. Lúcia Cortes da. Políticas sociais no MERCOSUL: desafios para uma integração regional com redução das desigualdades sociais. In: - (Org.). Estado e democracia: pluralidade de questões. Ponta Grossa: Editora UEPG, 2008. DAL PRÁ, Keli Regina. Transpondo fronteiras: os desafios do assistente social na garantia do acesso a saúde no Mercosul. 2006. Dissertação (Mestrado em Serviço Social). Programa de Pós-graduação em Serviço Social da Faculdade de Serviço Social da Pontifícia Universidade Católica do Rio Grande do Sul.

DRAIBE, Sônia Miriam. Coesão social e integração regional: a agenda social do MERCOSUL e os grandes desafios das políticas sociais integradas. Cad. Saúde Pública, Rio de Janeiro, 23 Sup 2, p.174-183, 2007. Disponível em: <http://www. scielo.br/pdf/csp/v23s2/06.pdf>. Acesso em: 16 fevereiro 2012.

FERREIRA, André Cassino. Interações na fronteira Brasil-Uruguai: um estudo de caso das cidades de Jaguarão-RS (Brasil) e Rio Branco (Uruguai). Revista Eletrônica Boletim do TEMPO, Ano 4, n.37, Rio, 2009. Disponível em: <http://www. tempopresente.org $/$ index 2 .php?option $=$ com_content\&do_pdf $=1 \&$ id $=5243>$. Acesso em: 15 março 2012.

INSTITUTO BRASILEIRO DE GEOGRAFIA E ESTATÍSTICA. Censo 2010. Disponível em: <http://www.ibge.gov.br/home/>. Acesso em 02 maio 2012.

MARTINS, José Renato Vieira; SILVA, Carolina Albuquerque. Políticas sociais e participação social: a construção de uma esfera pública regional no Mercosul. Boletim de Economia e Política Internacional. Instituto de Pesquisa Econômica Aplicada. n.5. jan./mar., 2011.

NOGUEIRA, Vera Maria Ribeiro. Fronteira MERCOSUL: um estudo sobre o direito à saúde. Relatório final de pesquisa. Departamento de Serviço Social. UFSC. $2005 \mathrm{a}$

; DAL PRÁ, Keli. MERCOSUL: expressões das desigualdades em saúde na linha da fronteira. Ser Social (UnB), v. 1, 2006. 
NOGUEIRA, Vera Maria Ribeiro; DAL PRA, Keli Regina; FERMIANO, Sabrina. A diversidade ética e política na garantia e fruição do direito à saúde nos municípios brasileiros da linha da fronteira do MERCOSUL. Cad. Saúde Pública, v.23, supl. 2 2007. Disponível em: <http://www.scielo.br/scielo.php?pid=S0102311X2007001400012\&script=sci_arttext $>$. Acesso em: 08 janeiro 2012.

RAMOS, Daniela Peixoto. Dimensão social do MERCOSUL: o caso brasileiro. La Dimensión Social Del MERCOSUR. Reunión de Ministros y Autoridades de Desarrollo Social Del MERCOSUR y Estados Asociados, Julio, 2006.

SIMIONATTO, Ivete. Sociedade civil, classes subalternas e construção democrática: cenários e desafios no âmbito do Mercosul. In: JORNADA INTERNACIONAL DE POLÍTICAS PÚBLICAS QUESTÃO SOCIAL E DESENVOLVIMENTO NO SÉCULO XXI, 3. São Luís - MA, 28 a 30 de agosto 2007. Disponível em: <http://www.joinpp.ufma.br/jornadas/joinppIII/html/ Trabalhos/EixoTematicoH/politicas_publicas_maranhao_Ivete\%20Simionatto. pdf>. Acesso em: 22 janeiro 2012.

SOUZA, Maura Luciane Conceição de Souza. A construção de políticas públicas regionais: saúde, educação assistência social e turismo. In: BRAGA MARTES, Ana Cristina; SPRANDEL, Marcia Anita. (Orgs.). Mercosul e as migrações: os movimentos nas fronteiras e a construção de políticas públicas regionais de integração. Brasília, 2008.

SPOSATI, Aldaíza. Álbum de fotografias da gestão da assistência social no Brasil na perspectiva do SUAS. In: CONFERÊNCIA NACIONAL DE ASSISTÊNCIA SOCIAL, 5. Brasília, 2005. Anais... Disponível em:<http://www.mds.gov. $\mathrm{br} /$ assistenciasocial/secretaria-nacional-de-assistencia-social-snas/cadernos / fotografia-da-assistencia-social-no-brasil-na-perspectiva-do-suas-2013-indicadoresda-gestao-municipal-da-politica-de-assistencia-social-no-brasil-2005-2006/ fotografia-da-assistencia-social-no-brasil-na-perspectiva-do-suas-2013-indicadoresda-gestao-municipal-da-politica-de-assistencia-social-no-brasil-2005-2006>. Acesso em: 10 fevereiro. 2012. 